\title{
Category Production Norms for 117 Concrete and Abstract Categories
}

\author{
Briony Banks ${ }^{1}$ and Louise Connell ${ }^{1,2}$ \\ ${ }^{1}$ Department of Psychology, Lancaster University \\ ${ }^{2}$ Department of Psychology, Maynooth University
}

\begin{abstract}
Author Note
Briony Banks https://orcid.org/0000-0003-3666-0222

Louise Connell https://orcid.org/0000-0002-5291-5267
\end{abstract}

Correspondence concerning this article should be addressed to Briony Banks, Department of Psychology, Fylde College, Lancaster University, Bailrigg, Lancaster, LA1 4YF, UK. E-mail:

b.banks@lancaster.ac.uk; or Louise Connell, Department of Psychology, Maynooth University, Maynooth Co., Kildare, Ireland. E-mail: louise.connell@mu.ie 


\begin{abstract}
We present a database of category production (aka semantic fluency) norms collected in the UK for 117 categories (67 concrete and 50 abstract). Participants verbally named as many category members as possible within 60 seconds, resulting in a large variety of over 2000 generated member concepts. The norms feature common measures of category production (production frequency, mean ordinal rank, first rank frequency), as well as response times for all first-named category members, and typicality ratings collected from a separate participant sample. We provide two versions of the dataset: a referential version that groups together responses that relate to the same referent (e.g., hippo, hippopotamus) and a full version that retains all original responses to enable future lexical analysis. Correlational analyses with previous norms from the US and UK demonstrate both consistencies and differences in English-language norms over time and between geographical regions. Further exploration of the norms reveals a number of structural and psycholinguistic differences between abstract and concrete categories. The data and analyses will be of use in the fields of cognitive psychology, neuropsychology, psycholinguistics, cognitive modelling, and to any researchers interested in semantic category structure. All data, including original participant recordings, are available at https://osf.io/jgcu6/.
\end{abstract}

Keywords: category production, semantic fluency, categories, abstract concepts, concrete concepts 


\section{Category Production Norms for 117 Concrete and Abstract Categories}

The ability to categorize concepts is a vital part of human cognition that allows us to understand and interpret the world around us. Accordingly, category production (also termed semantic or verbal fluency) is a widely used task in both cognitive and neuropsychology that is considered to reflect the structure and organization of the conceptual system, and particularly the taxonomy of concepts in semantic memory. A category production task simply requires participants to name concepts that belong to a given category, such as ANIMALS ${ }^{1}$ or EMOTIONS. It is used in a wide range of research, but particularly to investigate underlying categorical and conceptual structure (e.g., Crowe \& Prescott, 2003; Hampton \& Gardiner, 1983; Rosch, 1975; Troyer, 2000), semantic memory (e.g., Binney et al., 2018; Ryan et al., 2008), and executive function (e.g., Baldo \& Shimamura, 1998; Fisk \& Sharp, 2004; Shao et al., 2014). The task is also an important tool in clinical research (e.g., Bokat \& Goldberg, 2003; Henry \& Crawford, 2004) and diagnosis (e.g., Quaranta et al., 2016; Zhao et al., 2013). The importance of the category production task across multiple cognitive domains, and its use in both research and clinical settings, has led to numerous sets of category production norms being published in the last few decades. The first such norms were collected in the USA in 1957 (Cohen et al., 'The Connecticut Norms'), and were subsequently updated by Battig and Montague (1969) in their widely-cited set of norms. Since then, category production norms have been published in at least 9 different languages (see Figure 1), which have been used in a wide range of psychological research, including psycholinguistics (e.g., Stadthagen-Gonzalez et al., 2017; Warriner et al., 2013), memory (e.g., Ryan et al., 2008; Veling \& van Knippenberg, 2004), language comprehension (e.g., Federmeier et al., 2010; Jahncke et al., 2013), cognitive aging (e.g., Ferreira et al., 2019; Raz et al., 1998), and disorders such as schizophrenia (e.g.,

\footnotetext{
${ }^{1}$ To maximise clarity throughout the paper, we use uppercase for category names and lowercase italics for member concepts: for example, the category ANIMAL contains the members cat, dog, and elephant.
} 
Brébian et al., 2010; Vinogradov et al., 1992) and Alzheimer's disease (McDowd et al., 2011; Ober et al., 1991).

Category production norms have been collected from a variety of geographical regions, spanning North and South America, Europe, Asia and Australia (see Figure 1). Nevertheless, most English-language norms to date have been collected in the USA. To our knowledge, only four relatively small sets of category production norms have originated in the UK: Brown (1972; 28 categories), Hampton and Gardiner (1983; 12 categories from the Battig \& Montague norms), Morrow and Duffy (2005; 14 categories comparing data from younger and older adults), and Plant et al. (2011; 10 concrete noun and 10 ad-hoc verb categories). Thus, a contemporary and comprehensive set of category production norms from the UK is not currently available. Localizing category production norms by region is important because comparisons between norms have found that, while certain categories appear to have minimal differences between geographical regions, many other categories show large geocultural variation (Brown, 1978; Hampton \& Gardiner, 1983; Kantner \& Lindsay, 2014). For example, Brown (1978) compared norms collected at the same time in Scotland, UK (Brown, 1972) and the United States (Battig \& Montague, 1969). Across the 12 categories compared, half had relatively similar patterns of production frequency (CHEMICAL ELEMENTS, UNITS OF TIME, FOUR-FOOTED ANIMALS, COLOURS, MUSICAL INSTRUMENTS, PRECIOUS STONES: Pearson's $r=.88$ to .61 ) but some categories differed substantially between locations in their listed category members (OCCUPATIONS OR PROFESSIONS, ARTICLES OF CLOTHING, SPORTS and BIRDS: $r=.29$ to -.06$)$. Similar patterns were observed by Hampton and Gardiner (1983) when comparing their norms collected in London, UK, with Battig and Montague's (1969) American norms. Their most frequently-named member concepts were very similar for certain categories (e.g., for FRUIT, the top 4 members in both norms were apple, orange, pear and banana), but quite different for others (e.g., for SPORT, the top 3 member concepts produced by UK participants 
were soccer [football in the UK], rugby and tennis, but for USA participants these were [American]

football, baseball and basketball).

Figure 1.

Published category production norms per year, country and number of categories.

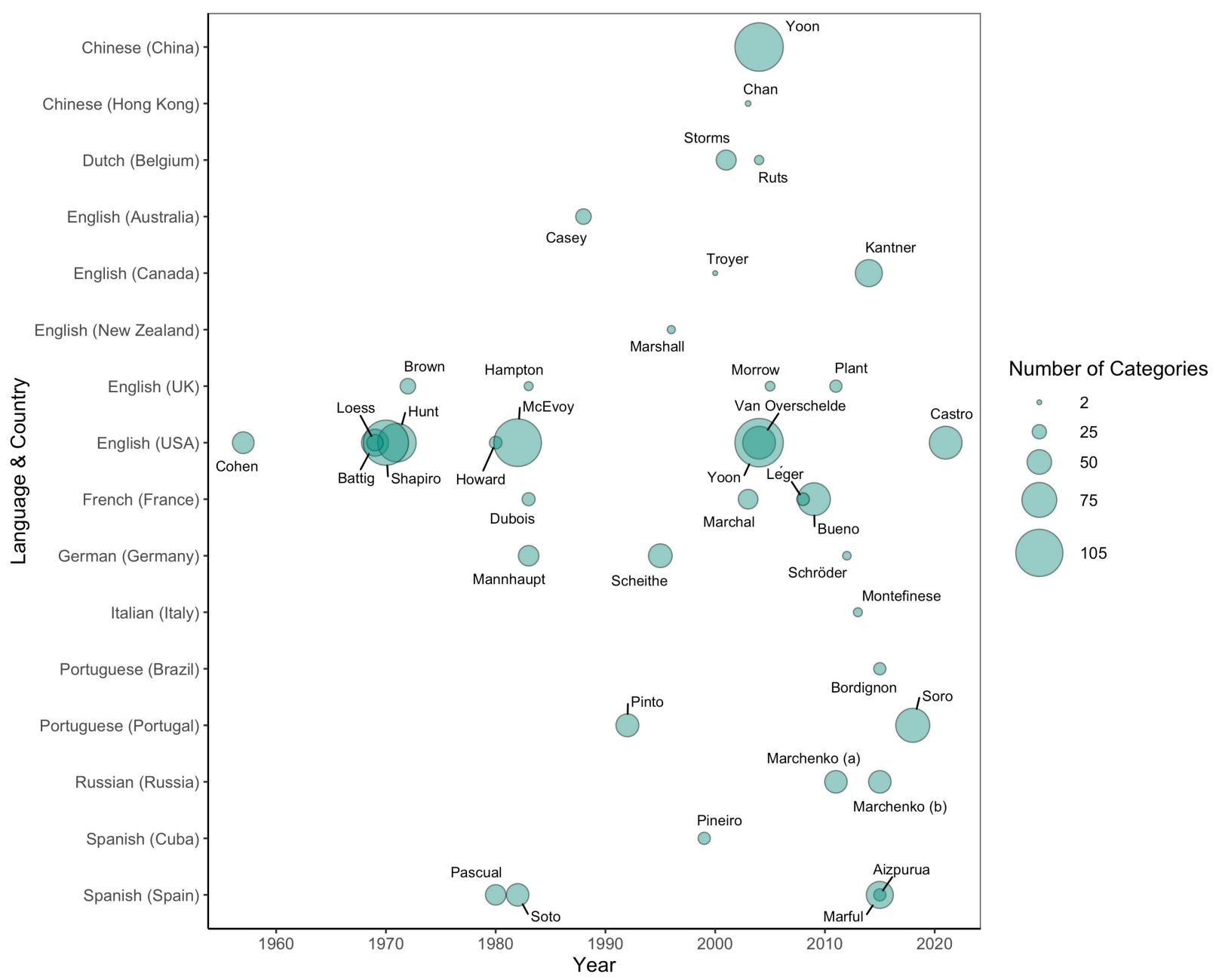

Note. Plotted studies represent normative category production data from adult, non-clinical populations published in a peer-reviewed journal, book or conference proceedings between 1957 and 2021, not all of which are currently available as datasets. Studies are ordered alphabetically by language and region; circle size indicates the number of categories included in the study, and labels indicate the first author.

Category structure can also vary over time. Van Overschelde et al. (2004) compared their norms with the Battig and Montague norms from 1969, both of which were collected in the USA: production 
frequency for the categories COLOURS and PARTS OF THE BODY were highly correlated $(r>.90$; e.g., the top 4 colours were identical in both studies: blue, red, green and yellow), while the categories A TYPE OF DANCE and A COLLEGE OR UNIVERSITY correlated weakly ( $r=.05$ and $r=.20$ respectively), possibly reflecting changing societal and cultural preferences in the 30 years between the studies (e.g., the top 4 dances in 1969 were waltz, frug, twist and foxtrot, while in 2004 they were ballet, tango, salsa and hip hop). Given the potential variation resulting from chronological and geographical differences in data collection, even within the same language, providing a contemporary set of norms collected in the UK is a timely and important addition to the study of semantic category structure and language.

To date, most category production norms have largely focused on concrete categories rather than abstract. While the Battig and Montague (1969) norms included a relatively diverse range of categories, they were nevertheless predominantly concrete in nature (e.g., VEGETABLE, SHIP, PART OF THE HUMAN BODY, PRECIOUS STONE). As many subsequent studies have simply replicated the Battig and Montague norms either in full or using a smaller subset (e.g., Howard, 1980; Marful et al., 2015; Marshall \& Parr, 1996; Storms, 2001), they too have focused on concrete categories, particularly those of historical interest to theories of conceptual processing, such as the basic-level categories outlined by Rosch (1973; e.g.,TREE, FRUIT, FISH, BIRD, MUSICAL INSTRUMENT, TOOL, CLOTHING, VEHICLE and FURNITURE), and the superordinate category ANIMAL. Indeed, category production norms have often focused on just a few high-frequency concrete categories (e.g., Chan et al., 2003; Hampton \& Gardiner, 1983; Morrow \& Duffy, 2005; Schröder et al., 2012; Troyer, 2000). As a result, far fewer category production norms have been collected for abstract categories; for example, only 15 of the original 56 categories by Battig and Montague could be classed as abstract (e.g., SCIENCE, PART OF SPEECH). These norms were replicated and extended by Van Overschelde et al. (2004) in English, and by Bueno \& Megherbi (2009) in French, but only one and three new abstract categories, respectively, were added (e.g., FOOTBALL PENALTY, ACADEMIC DISCIPLINE). A larger number of abstract categories were included 
by McEvoy and Nelson (1982; 26 abstract categories out of a total of 106, e.g., COLLEGE LEVEL and SEASON), and by Yoon et al. (2004; 26 abstract categories out of a total of 105, e.g., EMOTION and MATHEMATICAL OPERATION). Nevertheless, abstract categories still comprised a relatively small proportion of the data, and neither study purposely selected categories on the basis of abstractness; rather, they were selected based on expected category size (McEvoy \& Nelson, 1982), and for the purpose of cross-linguistic comparison (Yoon et al., 2004). To our knowledge, no previous category production norms have explicitly selected a substantial number of abstract categories, nor examined differences between them and concrete categories. Thus, less is known about the structure of abstract compared to concrete categories - for example, which member concepts are most frequently named, and the properties of generated concepts such as typicality or, indeed, concreteness. Given the current interest in the cognitive basis of abstract concepts (Borghi et al., 2017; Connell et al., 2018; Desai et al., 2018; Ponari et al., 2020), it seems timely to publish category production norms and comparisons for a larger number of abstract categories alongside more traditional concrete ones.

Certain measures of category production have commonly been used across sets of norms to examine the structure of categories and commonalities in participant responses, particularly how frequently each concept is produced per category (overall, or as the first-produced concept), and in what order (i.e., the ordinal rank of each concept per category). However, other measures may offer important insights to the process of category production; in particular, response times (RT) are a common implicit measure of conceptual processing but very few category production studies have measured or reported them. Van Overschelde et al. (2004) reported RTs for all responses given within 30 seconds, but these RTs were measured from the offset of typing a response (i.e., pressing an enter key when finished) rather than the onset, and so the measured latencies conflate both processing effort to think of a response and typing time to record it. Latencies from verbal responses can provide a more accurate measure of RT as they can be measured from the exact onset of speech following presentation 
of the category name, and have been used to examine neuropsychological deficits (Rohrer et al., 1995) and individual cognitive differences (Luo et al., 2010; Shao et al., 2014) in category production (though none of these studies published item or trial-level RT data). In the present norms, we therefore took the approach of asking participants to generate verbal responses, which enabled us to accurately measure RT for each first-named category member from the onset of speech following stimulus presentation. We report mean response latencies for item-level data (trial-level RTs per participant are provided as supplemental material), which may prove particularly useful in understanding the mechanisms behind generating initial category members.

At this point, it is worth noting two common inconsistencies in the methodologies of category production norms. Firstly, norming procedures often differ in the number of responses participants are allowed to make. Many studies replicate the original method employed by Cohen et al. (1957), which allowed as many responses as possible within 30 seconds, while others have limited the number of responses to just one (McEvoy \& Nelson, 1982), or the first few only (Kantner \& Lindsay, 2014; Montefinese et al., 2013; Yoon et al., 2004), potentially limiting the usefulness of these datasets as research tools. Allowing participants to generate many category members rather than just a few, and allowing a longer time limit (e.g., 60 seconds) so as to avoid cutoffs for particularly slow or profuse responses, allows the full diversity of category production responses to be recorded; we therefore took this approach in the norms reported here. Such data can potentially allow more in-depth study of category structure, for example semantic clustering (Troyer, 2000; Troyer et al., 1997), or the mechanisms behind activation of concepts from long-term memory (Banks et al., 2020).

Secondly, there are often differences in how studies handle lexical and morphological differences in participant responses, which affects the relevant frequency counts and ranks for member concepts. Category production tasks often generate responses that have the same core referent concept, but that vary in their precise wordform in terms of morphology (e.g., FRUIT - apple vs apples; 
EMOTION - happy vs happiness) or vocabulary/synonym choice (e.g., FURNITURE - couch vs sofa;

RELATIVE - dad vs father). Such responses have been handled in a variety of ways in previous norms. Some studies have largely preserved lexical and morphological distinctions apart from minor spelling variations, such as hi-rise and high-rise (e.g., Howard, 1980; Ruts et al., 2004; Yoon et al., 2004). However, others have grouped morphological variations (e.g., Battig \& Montague, 1969; Bueno \& Megherbi, 2009; Kantner \& Lindsay, 2014; Marchenko et al., 2015; McEvoy \& Nelson, 1982; Montefinese et al., 2013; Plant et al., 2011; Van Overschelde et al., 2004) or synonymous responses (e.g., Castro et al., 2021; Marful et al., 2015; Montefinese et al., 2013; Van Overschelde et al., 2004) under one lexical entry. Although any method of grouping responses is inherently subjective, it can be useful for examining broad similarities in semantic category structure. An alternative approach is to provide both grouped and full responses, as in Van Overschelde et al. (2004), allowing for easy comparison with previous norms which have used different data preparation methods, whilst also preserving more finegrained linguistic and semantic differences. We therefore used this approach in the current study, compiling two sets of our norms: a referential version with morphological and synonymous variations (i.e., those referring to the same core referent) grouped together under one label, and a full version with all lexical and morphological variations of responses preserved.

Finally, typicality ratings - that is, how good an example of its category is a particular concept are often included in category production norms alongside measures of frequency and ordinal rank (e.g., Izura et al., 2005; Léger et al., 2008; Montefinese et al., 2013; Plant et al., 2011; Ruts et al., 2004; Schröder et al., 2012). Typicality has frequently been studied as a measure of graded category structure (e.g., Osherson \& Smith, 1981; Rosch, 1975; Rosch et al., 1976), and can predict the frequency and rank order of category production responses (e.g., Hampton \& Gardiner, 1983; Mervis et al., 1976; Montefinese et al., 2013; Uyeda \& Mandler, 1980). In addition to our category production data, we thus 
include typicality ratings for the majority of category-member pairs from a separate sample of participants.

\section{The Present Study}

To summarize, we present a large set of category production norms that has several advantages over existing norms in the English language. First, to the best of the authors' knowledge, they comprise the largest and most contemporary set of category production norms collected in the UK. Second, they comprise production norms for the largest number of concrete and abstract categories in English to date: 67 concrete and 50 abstract categories (117 in total). Given the large number of categories, the norms span a variety of category levels and subtypes: subordinate, basic and superordinate taxonomic levels, as well as semantic categorical divisions such as natural and artefact, animate and inanimate, social and non-social category types. Third, we provide two versions of our category production norms: a referential version (which groups responses with the same referent, and forms the basis of the analyses reported here) and a full version (which leaves each response in its original wordform, with analyses included as supplemental material). Researchers may select the most appropriate version for their required purpose. Fourth, by allowing participants to provide as many responses as possible within 60 seconds, we have generated a very large and comprehensive dataset for future research, containing 2451 unique category-member pairs in the referential version (5474 including idiosyncratic items produced by only one participant), or 2558 unique pairs in the full version (6448 including idiosyncratic items). Fifth, we include response times (RT) for all first named concepts per category. Although we do not report RTs for every response, the majority of audio recordings (those where participants gave permission) are available for other researchers to calculate such timings if desired. Sixth, and final, we provide typicality ratings for 2234 member concepts within their categories ( $87 \%$ of items in the full version; $80 \%$ of items in the referential version), collected from a separate sample of participants, to enable analysis of categorical gradedness. 
To validate the norms, we present an analytical comparison between the present data and previous sets of English-language norms, both from the UK (Hampton \& Gardiner, 1983) and the USA (Van Overschelde et al., 2004). We also report a number of structural and psycholinguistic differences between abstract and concrete categories, which highlights the importance of making available category production norms for abstract as well as concrete categories. These norms have already proven useful in our own lab, where we have used them to study and computationally model the process of conceptual activation during category production (Banks et al., 2020). We hope that the norms will be of interest and use to researchers in a broad range of cognitive and psychological research, and any field seeking to gain insight into the processes involved in selecting and retrieving category members from semantic memory.

\section{Study 1: Category Production Norms}

\section{Methods: Category Production Norming}

\section{Participants}

Sixty-four participants recruited from Lancaster University took part for payment of $£ 3.50 \mathrm{GBP}$. Three participants were excluded as they were non-native speakers of English (i.e., questioning during debriefing revealed that they had misunderstood the screening criteria), and one was excluded for providing too few responses ( $M<2$ responses per category). Of the remaining 60 participants, all had English as their native language, 46 were female, mean age was 21.72 years $(S D=5.73)$, and 52 were right-handed. The study received ethical approval from the Lancaster University Faculty of Science and Technology Research Ethics Committee. Participants gave their informed consent to take part and to publicly share their anonymised data, and could additionally opt in to sharing publicly their original voice recordings with anonymised filenames: 52 out of 60 participants consented to do so.

\section{Materials}


We selected 117 categories representing a range of concrete and abstract concepts (see Table 1), the majority of which were selected from the categorization literature (Battig \& Montague, 1969; Capitani et al., 2003; Larochelle et al., 2000; McEvoy \& Nelson, 1982; Rosch, 1975; Uyeda \& Mandler, 1980; Van Overschelde et al., 2004). Where possible, categories spanned multiple taxonomic levels, such as the basic (e.g. BIRD), superordinate (e.g. ANIMAL), and subordinate (e.g. WATER BIRD) levels. The 67 concrete categories represented a range of living and non-living, animate and inanimate, artefact and natural, and biological and nonbiological semantic categories. We included many common concrete categories that have been frequently investigated in the categorization literature (e.g., FRUIT, MUSICAL INSTRUMENT), as well as other less common concrete categories (e.g., BIRD OF PREY, ROOM IN A HOUSE). The 50 abstract categories covered social and non-social, human and non-human, internal (i.e., relating to internal human experience) and external semantic categories. Some of these categories had been previously included in category production norms (e.g., SCIENCE, EMOTION) while others were novel to the present study. Some of the novel abstract categories were subordinate (e.g., VIOLENT CRIME, NEGATIVE EMOTION) or modified variants of those already selected from the literature (e.g., ROYAL TITLE), while others were created de novo by the authors based on categorical distinctions in WordNet (Princeton University, 2010) for abstract entities (e.g., PERSONAL QUALITY, FRACTION, SOCIAL GATHERING). All categories were piloted on participants not involved in the main study to ensure that they were understandable. Categories were divided into three lists of 39 categories each, counterbalanced as much as possible across the abstract/concrete dimension. Categories that constituted a subset of another category (e.g. WATER BIRD, BIRD) were not included in the same stimulus list. Four additional categories (BREAD, CIRCUS ACT, FOOTWEAR and CONTINENT) that were not featured in the main task were used as practice items to ensure participants had understood the instructions. 
Table 1.

All 117 categories featured in the category production norms, comprising 50 abstract and 67 concrete categories.

\begin{tabular}{llll}
\hline Abstract categories & & & \\
\hline Academic subject & Injury & Profession & Team sport \\
Art form & Legal profession & Psychological illness & Three-dimensional shape \\
Artistic movement & Medical specialty & Racket sport & Time of day \\
Book genre & Military title & Religion & Two dimensional shape \\
Crime & Month & Royal title & Type of word \\
Day of the week & Negative emotion & Science & Unit of length \\
Disease & Negative personal quality & Season & Unit of time \\
Emotion & Non-violent crime & Social gathering & Unit of weight \\
Family relationship & Personal quality & Social relationship & Violent crime \\
Fraction & Political system & Sport & Water sport \\
Geometric shape & Positive emotion & Statistical term & Winter sport \\
Healthcare profession & Positive personal quality & Supernatural being & \\
Infectious disease & Prime number & Symptom of illness & \\
& & & \\
\hline
\end{tabular}

Concrete categories

\begin{tabular}{llll}
\hline Alcoholic drink & Dairy product & Human dwelling & Religious building \\
Animal & Drug & Insect & Rodent \\
Bathroom fixture & Fabric & Jewellery & Room in a house \\
Bird & Farm animal & Kitchen appliance & Snake \\
Bird of prey & Fish & Kitchen utensil & Spice \\
Boat & Flower & Living room furniture & Stinging insect \\
Body of water & Four-legged animal & Meat & String instrument \\
Breed of dog & Four-wheeled vehicle & Metal & Tool \\
Building & Fruit & Musical instrument & Tree \\
Building material & Fuel & Natural landform & Two-wheeled vehicle \\
Camping equipment & Furniture & Nut & Vegetable \\
Carpenter's tool & Gardening tool & Part of a boat & Vehicle \\
Chemical element & Gemstone & Part of a building & Water bird \\
Citrus fruit & Green vegetable & Part of a tree & Weapon \\
Clothing & Hair colour & Part of the body & Weather \\
Colour & Hat & Part of the face & Wind instrument \\
Cosmetic & Herb & Reading material & \\
\hline
\end{tabular}

\section{Procedure}


Following consent procedures, participants sat individually in front of a computer screen while wearing a headset microphone. They read instructions that asked them to name aloud as many concepts as possible that belonged to each category, within a maximum of 60 seconds. Participants triggered the start of each trial by pressing the space bar on the keyboard. Each trial began with a fixation cross for $500 \mathrm{~ms}$ followed by the category name presented in capital letters in the center of the screen. The category name remained onscreen until participants could not name any more concepts and pressed the spacebar to end the trial, or until the trial timed out automatically after 60 seconds. When a trial ended, the words 'Press space bar when ready' then appeared onscreen until participants triggered the next trial; timing between categories was thus self-paced and participants could take a short break between categories if required. Participants first carried out the four practice trials, and were then randomly assigned to one of the three category lists. Each list was presented to 20 participants, and categories from each list were presented in a randomized order for each participant. Verbal responses were audio-recorded through a headset microphone and were simultaneously transcribed during the task by the experimenter (hidden from the participant's view behind a panel screen); these transcriptions were later verified via the audio recordings and unintelligible responses (comprising $0.08 \%$ of all responses) were discarded. The entire experimental procedure took approximately 20 minutes, after which participants provided demographic information and were debriefed by the experimenter.

\section{Norms Data Preparation}

Full version. All transcribed responses were included in this dataset exactly as they were spoken, preserving morphological differences such as agreement and grammatical tense, and using British English spellings.

Referential version. For each category, responses which referred to the same core referent were combined under one grouping label: specifically, the response most frequently produced by 
participants. This referential grouping applied to any morphological variations (e.g., singular and plural forms of a word such as ANIMAL - cheetah/cheetahs $\rightarrow$ cheetah; different parts of speech such as EMOTION - happy/happiness $\rightarrow$ happy) and synonymous variations (e.g., FAMILY RELATIONSHIP mum/mother $\rightarrow$ mother) in the terminology used to label a referent. Where an equal number of responses were produced for each variant label (e.g., an equal number of participants named rucksack and backpack for the category CAMPING EQUIPMENT), we selected the word with the higher frequency in British English as the grouping label (e.g., rucksack/backpack $\rightarrow$ rucksack; based on frequency counts for unigrams and bigrams from the SUBTLEX-UK corpus: van Heuven et al., 2014). If neither variant label appeared in the SUBTLEX-UK corpus (e.g., sandwich maker and sandwich toaster for the category KITCHEN APPLIANCE), we carried out a search on British English texts from 1999-2019 in the Google Books Ngram Viewer (http:// books.google.com/ngrams), and selected the word with the higher frequency count as the grouping label (e.g., sandwich maker); 20 items were selected for use this way. In three cases, an equal number of participants produced full (two-word) and abbreviated (single-word) variants of a response (e.g., CARPENTER'S TOOL - spirit level / level), where the single-word term was polysemous and therefore frequency counts would be inaccurate; for these cases, the unabbreviated version was selected as the grouping label to avoid ambiguity. Responses that were closely related but did not refer to the same core referent were maintained as separate items, such as subordinate categorical distinctions (e.g., wine and white wine).

Category production measures. We calculated two measures of category production at the category level: category size was the total number of unique, non-idiosyncratic member concepts (i.e., concepts produced by more than one participant) that were listed for a given category across the entire set of participants; mean number of responses was the average number of responses produced by each participant for a given category, calculated as the total number of non-idiosyncratic responses collated for that category divided by the number of participants who saw that category. 
At the item level, we calculated several measures of category production: production frequency (the number of participants who named a particular member concept within its category); mean rank (the mean ordinal position of a particular member concept within its category); and first rank frequency (the number of participants who named a particular member concept first within its category, where responses that were never named as a first response by any participant were excluded rather than given a frequency of zero). We calculated the mean response time (RT) for first-named member concepts within their category, where RT per trial was measured from the onset of the category name until onset of speech to name the first member concept. Disfluencies were disregarded and speech onset was calculated in Praat (Boersma \& Weenink, 2018).

The Appendix contains a full list of variables featured in the norms; all measures were calculated separately for the full and referential versions. Summary statistics and Spearman's correlations between all measures of category production were calculated in JASP version 0.14.1 (JASP Team, 2020).

\section{Methods: Typicality Ratings}

\section{Participants}

In order to recruit a sample with similar linguistic experience to the category production study, we restricted recruitment to native speakers of English who were UK nationals on the online research crowdsourcing tool Prolific. A total of 141 native speakers of English took part in this study via Prolific; however, fourteen participants' submissions were rejected because their ratings did not pass our quality control checks (i.e., they were not paid and their data were excluded; see Data Preparation below). New participants were recruited via Prolific until we reached $N=12$ for all stimulus lists (participants who were not rejected were able to rate multiple lists). A total of 127 participants were included in the final analysis ( 88 female, mean age $=31.23$ years, $S D=10.33$ years, 111 right-handed) and received $f 1.75$ GBP for participation. Ethical approval was gained from the Lancaster University Faculty of Science and Technology Research Ethics Committee, and all participants gave their informed consent to take part 
and openly share their anonymised data.

\section{Materials}

Stimuli for typicality ratings comprised 2280 category-member word pairs: 2234 pairs from the full version of the present norms (this dataset comprised all items used in the analysis of Banks et al., 2020), plus an additional 46 pairs that were rated for use in a separate study and do not feature in the present norms. Category-member pairs were pseudo-randomly divided into 20 stimulus lists, whereby each category was distributed across lists as equally as possible, and member concepts that appeared with more than one category (e.g. eagle for the categories BIRD and BIRD OF PREY) were allocated to separate lists. In addition, production frequency (see Measures of Category Production) and log word frequency (LgSUBTLWF, from the English Lexicon Project, Balota et al., 2007) were counterbalanced across lists (mean production frequency per list $=5.73(S D=4.65)$ ranging from 5.24 to 6.05 , with no significant difference between lists, $F(19)=0.28, p=0.999 ;$ mean LgSUBTLWF per list $=2.59(\mathrm{SD}=0.87)$ ranging from 2.48 to 2.74 , with no significant difference between lists, $F(19)=0.98, p=0.485$ ).

We selected 80 items from our stimuli with known typicality ratings from previous studies (Armstrong et al., 1983; Rosch, 1975; Uyeda \& Mandler, 1980) to use as quality control checks in online data collection. Half of these had high typicality ratings (i.e., $<1.6$ on a scale of $1-7,1$ being high typicality and 7 being low typicality; $M=1.34, S D=0.19$ ) and half had low typicality ratings (i.e., $>3.7, M=4.39, S D$ $=0.54)$; each stimulus list contained four high-typicality and four low-typicality control items. Two further items not featured in our stimuli were used as scale calibrators: one high typicality (TOY - doll) and one low typicality (VEHICLE - surfboard), presented at the start of each stimulus list; these items are not included in the present norms. Each stimulus list therefore comprised 120 items (category-member word pairs), including the two calibrator and eight control items.

\section{Procedure}

Each stimulus list was presented in a randomised order in an online questionnaire via Qualtrics. 
For each item, the category name was presented in capital letters in the centre of the screen, above the framing question "How good an example of this category is/are a/an X(s)?" (e.g., ANIMAL: "How good an example of this category is a cat?"), and the rating scale 1-5 (with 1 being a "very poor" example, and 5 being a "very good" example). Participants were asked to base their ratings on their own judgements. Only one response per item was allowed, but participants could also indicate if they did not know the meaning of the category or the category member (no ratings were recorded for such trials). The entire ratings procedure took approximately 15 minutes. At the end of the stimulus list, participants provided demographic information and read a study debrief.

\section{Typicality Data Preparation}

To check the quality of the online data, each participant's ratings for the control items were correlated with ratings gained from previous studies. If the Pearson's correlation coefficient was $r<.30$, and the variance of that participant's data was close to zero, then the participant was excluded for failing to adequately attend to and/or understand the task. Fourteen participants were excluded on this basis (see Participants). We calculated inter-rater reliability for each stimulus list using the split-half method, whereby participants were randomly divided into two equal groups (odd vs. even-numbered) and raw typicality ratings were correlated using the Spearman-Brown correction $([2 * r] /[1+r])$. Interrater reliability was high for each stimulus list ( $r>.80$ for all lists, range $.81-.91)$. For each categorymember pair, we then calculated the mean typicality rating across all participants. These item-level ratings are provided in the full category production dataset. For the referential version of the data, where responses were grouped according to their core referent, the mean typicality rating was used for grouped items (e.g., for the category-member pair ANIMAL - cheetah, both singular and plural responses were grouped together, thus the mean typicality rating for cheetah and cheetahs was used). Correlations between typicality ratings and measures of category production were calculated and plotted using the ggcorr function from the GGally package (Schloerke et al., 2021) in R Studio version 
1.3.959. As the measures were differentially distributed, which can artificially restrict the value of Pearson's correlation (J. Cohen et al., 2013), we opted to calculate Spearman's correlation as the measure of association between variables.

\section{Results}

Summary statistics across all categories for both full and referential versions of the norms are shown in Table 2. Analyses of the norms reported in this section focus on the referential version of the data, although analyses of the full version are also provided as supplemental material at https://osf.io/jgcu6/. Idiosyncratic items (i.e., category members named by only one participant; also provided as supplementary material) were excluded from all analyses, resulting in a total of 2451 distinct category-member pairs for the referential dataset at the item level. As the analyses reported here were exploratory, no inferential statistics are reported.

At the category level, Figure 2 shows category size (i.e., total number of unique member concepts) and mean number of responses (i.e., number of member concepts listed by an average participant) for each category. Category size ranged from a very small set of 6 member concepts (TWOWHEELED VEHICLE, RACKET SPORT and TYPE OF WORD) to a very large set of 69 (ANIMAL). Participants named on average 6.47 concepts per category, but this number was highly variable and ranged from 2.00 concepts (ARTISTIC MOVEMENT) to 17.85 concepts (ANIMAL). For certain bounded categories, the category size and mean number of responses were very similar (i.e., MONTH and DAY OF THE WEEK), indicating that participants tended to consistently name the full set of possible member concepts (e.g., almost all participants named all seven days of the week). For other categories, responses were more variable; for example, ANIMAL, EMOTION and TREE have large differences between the total category size and mean number of responses, indicating greater inter-participant variability in the subset of member concepts each individual produced for that category. For instance, although participants listed 
on average 7 different types of EMOTION, it represented only $26 \%$ of the total category size of 27

members.

Table 2.

Summary statistics for category production measures across all 117 categories (both versions of norms, excluding idiosyncratic items), with total number of items for each measure and the mean and standard deviation.

\begin{tabular}{lcccccc}
\hline Variable & \multicolumn{3}{c}{ Referential version } & \multicolumn{3}{c}{ Full version } \\
\cline { 2 - 6 } & $N$ & Mean & SD & $N$ & Mean & SD \\
\hline Category level & & & & & & \\
Category size & 2451 & 20.95 & 10.39 & 2558 & 21.86 & 11.08 \\
Mean number of responses & 14684 & 6.47 & 3.05 & 13817 & 6.10 & 2.94 \\
& & & & & & \\
Item level & & & & & & \\
Production frequency & 2451 & 5.99 & 4.96 & 2558 & 5.40 & 4.46 \\
Mean rank & 2451 & 6.44 & 3.68 & 2558 & 6.23 & 3.67 \\
First-rank frequency & 676 & 3.16 & 3.60 & 722 & 2.88 & 3.21 \\
RT (seconds) first response & 676 & 3.65 & 2.12 & 722 & 3.56 & 2.08 \\
Typicality rating & 1956 & 4.18 & 0.67 & 2234 & 4.21 & 0.66 \\
\hline
\end{tabular}


Figure 2.

Lollipop plot of category size and mean number of responses per category

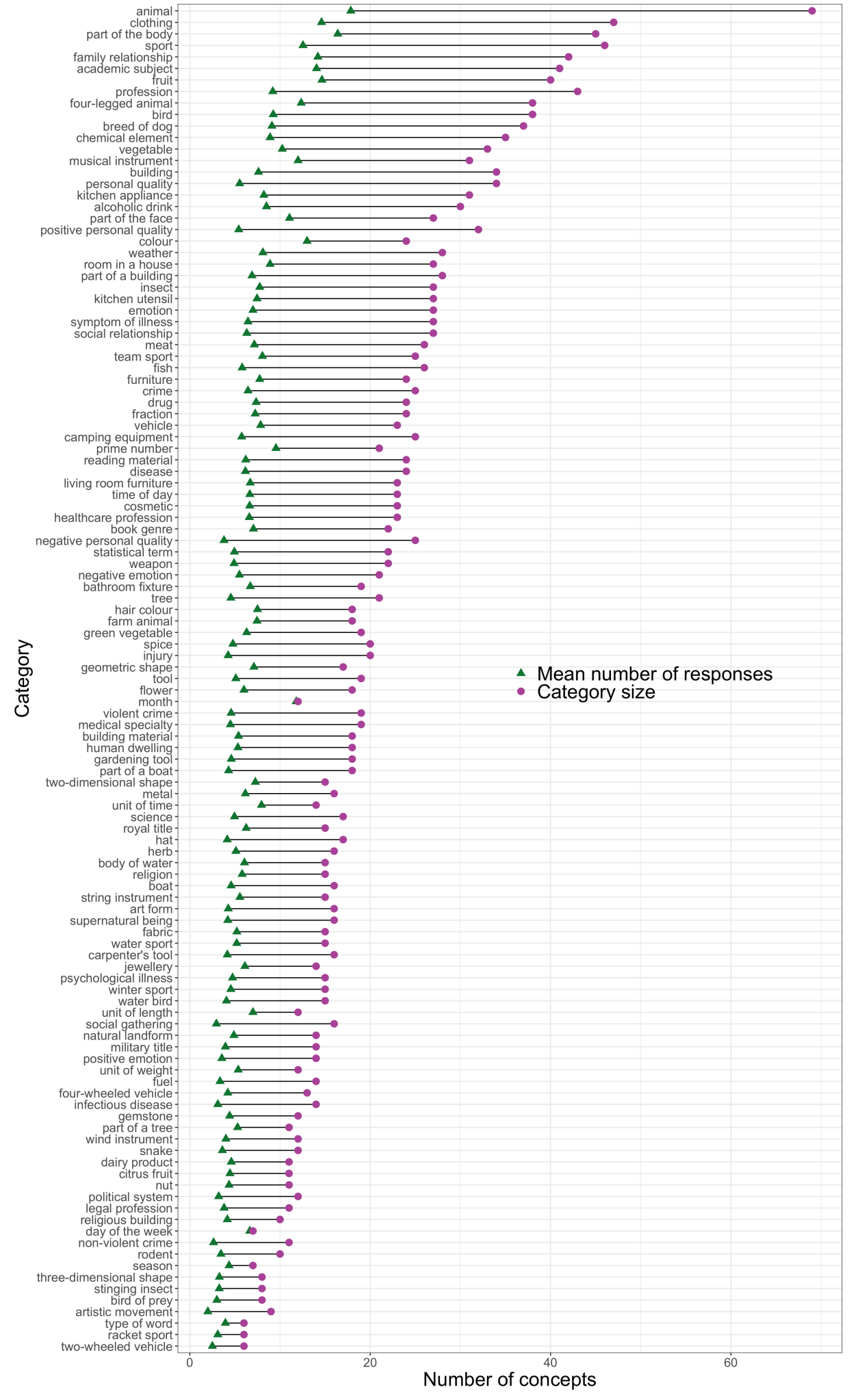


At the item level, we carried out Spearman's correlations between all four measures of category production and typicality (see Figure 2). Both production frequency and first-rank frequency were moderately negatively correlated with mean ordinal rank, whereby more frequent responses were named earlier in the task. First-response RTs were negatively correlated with production frequency (more frequently-produced responses were named faster), but were only very weakly correlated with first rank frequency and not at all with mean rank. Typicality ratings were moderately correlated with both frequency measures (concepts with higher typicality ratings were named more frequently overall and as the first response), but were more weakly and negatively correlated with mean rank and RT (more typical responses were named earlier and faster).

\section{Figure 3.}

Correlation heatmap (Spearman's correlations) between measures of category production and typicality.

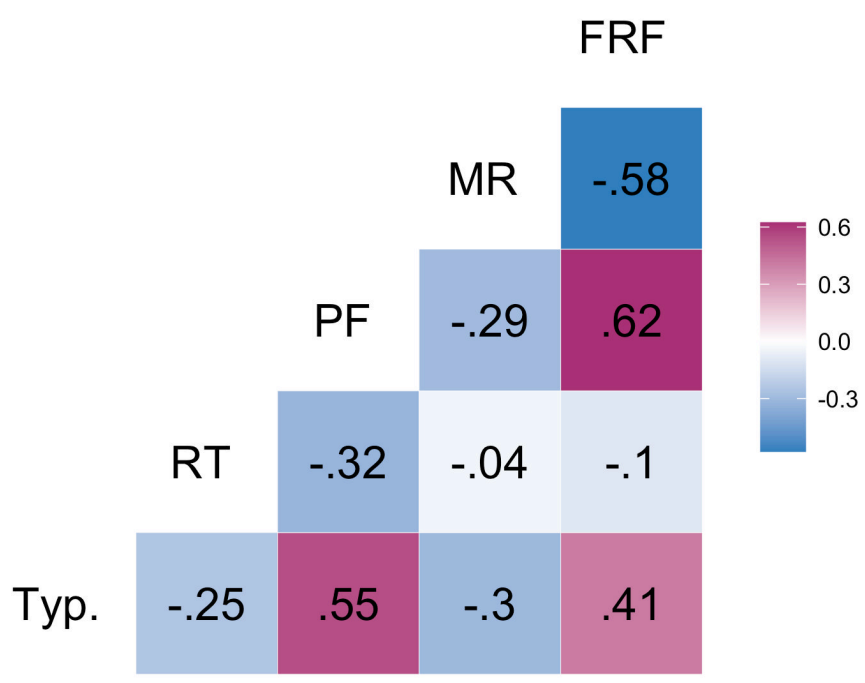

Note. $\mathrm{FRF}=$ first-rank frequency; $\mathrm{MR}=$ mean rank; $\mathrm{PF}=$ production frequency; $\mathrm{RT}=$ mean first-response time; Typ. = typicality rating. 


\section{Comparisons with Previous Norms}

We compared our current norms with two previous sets of category production norms: Van Overschelde et al. (2004), a contemporary replication of the Battig and Montague norms collected in the USA; and Hampton and Gardiner (1983), an older set of norms collected in the UK for 12 categories. The goal of this comparison was to allow us to analyze differences in category production across geographical regions but within a relatively similar timeframe (i.e., $21^{\text {st }}$ century norms from the UK versus USA), and across time periods but within the same region (i.e., UK norms from late 2010s versus early 1980s). As not all categories in our norms overlapped with the two other studies, we analyzed only the 44 matching categories from Van Overschelde et al. and the 11 matching categories from Hampton \& Gardiner. Several category names in Van Overschelde's norms were slightly different to our category names, sometimes due to what appeared to be dialectal differences; in such cases, we matched the categories where we judged that they referred to the same semantic class (e.g., ALCOHOLIC BEVERAGE and ALCOHOLIC DRINK; RELATIVE and FAMILY RELATIONSHIP). Because the majority of responses were reported in the singular form by Overschelde et al. and Hampton and Gardiner, we used the singular form of all items in our dataset for the purpose of comparison (e.g., for PART OF THE BODY, we used hand instead of hands). Minor differences in spelling were also standardized across the three datasets as British English spellings (e.g., meter $\rightarrow$ metre; chicken pox $\rightarrow$ chickenpox; sulfur $\rightarrow$ sulphur), and repetitions of category names were added for consistency (e.g. for the category TREE, the response apple was consistently rendered as apple tree). Idiosyncratic items were excluded from all norms before comparison; Van Overschelde et al.'s norms already excluded responses produced by $<5 \%$ of participants.

All three measures of category production (production frequency, mean rank, and first rank frequency) were available for comparison in Van Overschelde et al.'s norms, but only production frequency and first-rank frequency were available in Hampton and Gardiner's norms. As the variables 
being compared were differentially distributed, as before we opted to calculate Spearman's correlation as the measure of association between variables (calculated in $\mathrm{R}$ Studio version 1.3.959 using the dplyr package: Wickham et al., 2021); these were first calculated globally (i.e., based on all category-member pairs) and then per category. To capture differences in the overlap between responses (i.e., to what extent particular responses were given in one study but not in another), we ran correlations of production frequency on category members produced by participants in either relevant study, where absent category members were allocated a production frequency of zero (e.g., the item BIRD - swan had a production frequency of 5 in our norms, but was absent from Van Overschelde's and so received a value of 0). For first-rank frequency and mean rank, correlations were based only on items produced in both relevant studies (following Brown, 1978; Kantner \& Lindsay, 2014). Note that there were insufficient data to calculate per-category correlations for first-rank frequency (e.g., many categories had 0-2 overlapping first-named members), and so we report global correlations only.

Cross-region comparisons. Overall, the present UK norms showed a variable resemblance to the Van Overschelde et al. (2004) USA norms. The global correlation for production frequency was moderate at best ( $\rho=.35, N=1376)$ while correlations for mean rank $(\rho=.75, N=595)$ and first rank frequency $(\rho=.63, N=201)$ were much higher. This pattern is largely due to a relatively low overlap in produced items for certain categories (i.e., many items produced in one set of norms were not produced in the other), but matching items between norms were produced in a similar order and at similar firstresponse frequency ${ }^{2}$.

Correlations for individual categories showed large geographic variation (see Figure 4). While certain categories are very similar between the UK and USA (e.g., UNIT OF TIME, COLOUR, TYPE OF WORD), others greatly differ (e.g., WEATHER, VEHICLE, TREE). These differences appear to be driven by

\footnotetext{
${ }^{2}$ Indeed, when only matching items between studies were analysed, the correlation for production frequency was much higher $(\rho=.72)$.
} 
three main factors. Firstly, differences in the natural environment meant that many biological categories had quite different member concepts per region (e.g., half of US participants' responses to the category SNAKE are species native to North America but not Europe, and were never named by our UK participants). Secondly, but distinctly from the first point, cultural differences had a similar effect on some social and artifact categories (e.g., for ALCOHOLIC DRINK, 45\% UK participants produced cider compared to zero US participants ${ }^{3}$, and out of a total of 40 responses across both studies, only 9 were produced in both - e.g., vodka, whiskey and beer). Lastly, as we did not attempt to control for dialect, differences in terminology were also responsible for some differences in listed category members (e.g., the most frequent responses for the category FUEL were petrol in the UK and gasoline in the US norms, which in fact have the same referent of refined petroleum). These cross-region patterns closely match previous UK-US comparisons (Brown, 1978; Hampton \& Gardiner, 1983), where certain categories were found to be highly consistent between regions (e.g., CHEMICAL ELEMENT, UNIT OF TIME, COLOUR, PRECIOUS STONE, FRUIT - all of which were also highly correlated in the present analysis), while others much less so (e.g., CLOTHING, SPORT, FISH - again, matching the present pattern of results). Critically, the differences we observe here between contemporary category production in the UK versus USA highlight the importance of using geographically-appropriate norms in psychological research.

\footnotetext{
${ }^{3}$ In the US, cider is typically non-alcoholic while hard cider is alcoholic; nonetheless, this geographic difference between norms is cultural rather than terminological because both cider and hard cider are absent from the US norms for ALCOHOLIC DRINK.
} 


\section{Figure 4.}

Dot plots of the cross-region comparison between current category production norms (UK) and norms from Van Overschelde et al. (2004: USA), showing per-category Spearman's correlations for production frequency and mean rank.
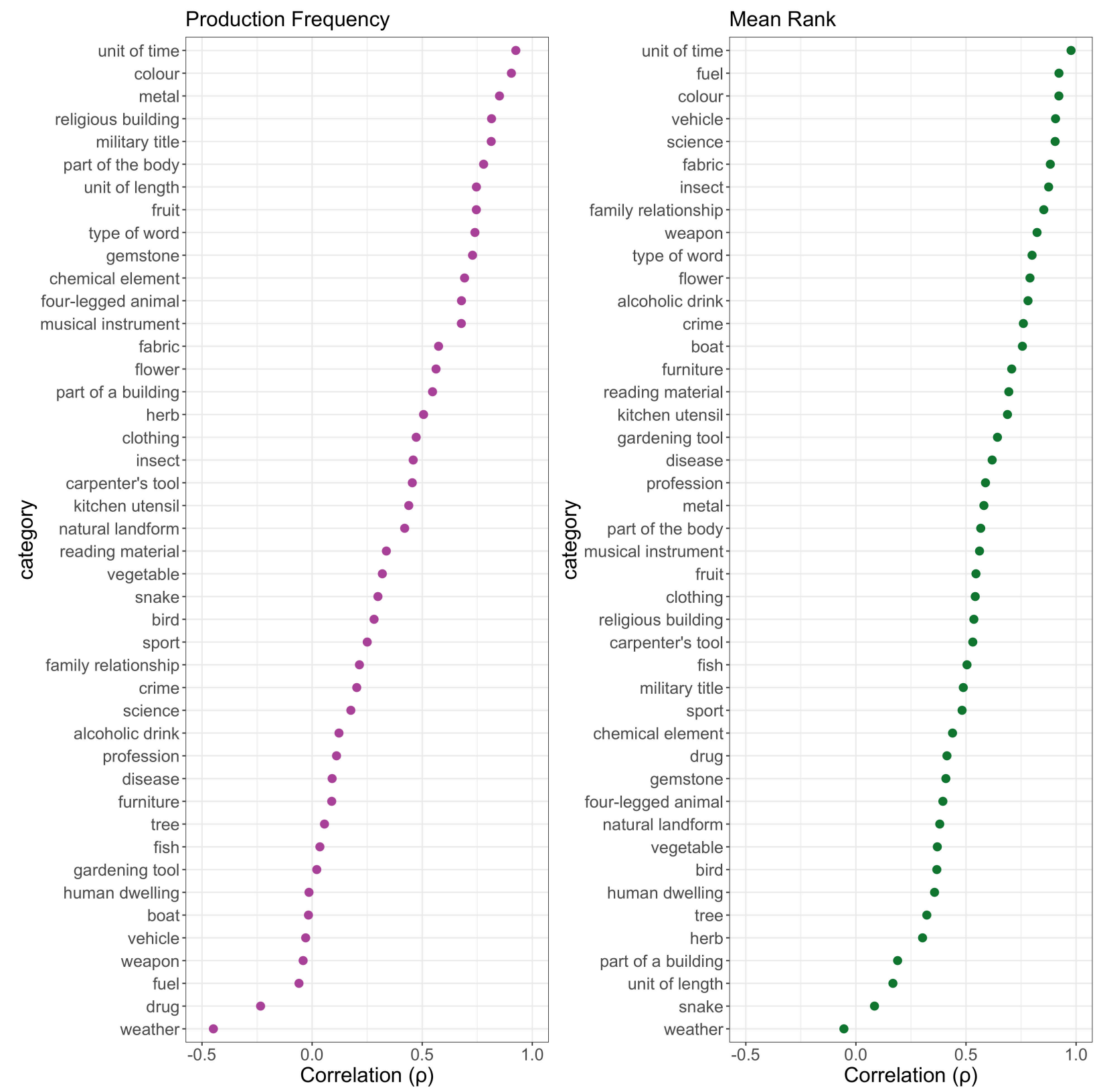

Note: Categories in each plot are ordered by size of correlation coefficient (high to low). Correlations for production frequency include items produced in either study; correlations for mean rank only include matching items produced in both studies. 
Cross-time comparisons. The present norms also showed a variable resemblance to the Hampton and Gardiner (1983) norms, collected more than 35 years previously in the UK. The global correlation for production frequency was moderate $(\rho=.45, N=584)^{4}$, as was that for first rank frequency $(\rho=.43, N=54)$, which suggests that there was limited overlap in the member concepts produced for each category as well as some differences in which items was named first.

Per-category correlations for production frequency were moderate to low (see Figure 5). Category production responses were somewhat consistent between 1980s and 2010s UK samples for natural categories such as FRUIT, INSECT, FLOWER and VEGETABLE, but are far less so for others such as WEAPON, FISH, BIRD and SPORT. Cultural changes can potentially explain many of these differences. For example, in the category CLOTHING, hoodie was named by $45 \%$ participants in our norms but was never given as a response in the 1983 norms. Similarly, basketball and running are both frequent responses for the category SPORT in our norms (named by $80 \%$ and $45 \%$ participants respectively) but were only named by $26 \%$ of participants each in the 1980 s. Even natural categories can potentially capture cultural shifts, such as differences in the category FISH which likely reflect changes in UK fisheating habits: trout and plaice were named by $>50 \%$ participants in 1983 , but were named by only $15 \%$ participants in the current data, while tuna is presently the most popular response (named by $60 \%$ participants in our norms compared to $19 \%$ in 1983). Similar changes over time were observed by Van Overschelde et al. (2004) in the USA, where the largest shifts occurred in culturally-dependent categories like TYPE OF MUSIC or TYPE OF DANCE but also in less obvious categories such as CLOTHING and VEGETABLES.

\footnotetext{
${ }^{4}$ When only matching items were analysed, the correlation for production frequency was stronger, $\rho=$ $.64, N=267$.
} 


\section{Figure 5.}

Dot plot of the cross-time comparison between current category production norms (UK) and norms from Hampton \& Gardiner (1983: UK), showing per-category Spearman's correlations for production frequency.

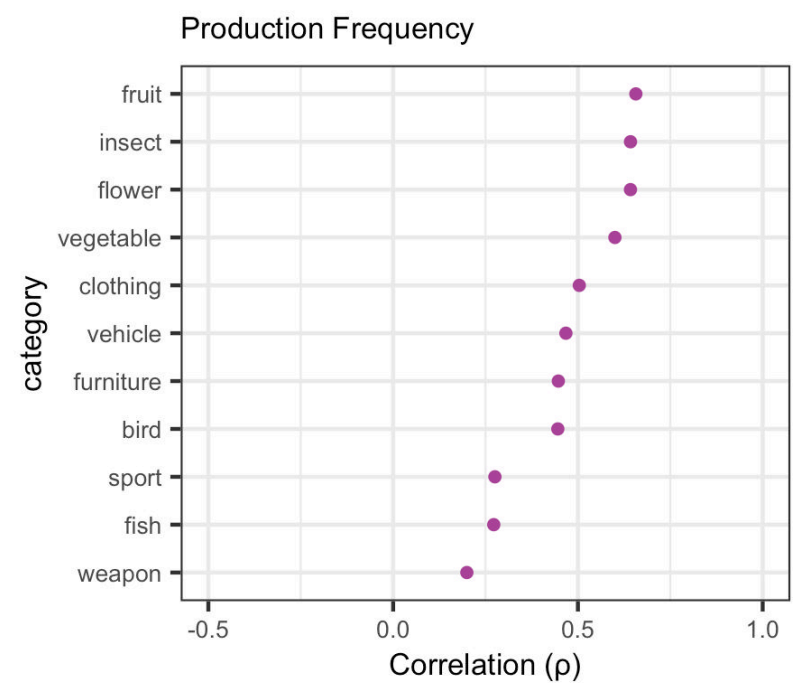

\section{Study 2: Concrete versus Abstract Categories}

As the present category production norms are the first to collect data for such a wide variety of abstract categories, our goal in this second study is to explore and present what differences exist between abstract and concrete categories in category production behaviour.

\section{Method}

We examined category- and item-level variables for all 2451 member concepts in the referential version of our category production norms, separately for the 67 concrete and 50 abstract categories. As in Study 1, idiosyncratic items were excluded from analysis. In addition, we examined how member concepts for abstract and concrete categories compared across four additional psycholinguistic variables: word frequency (Zipf scores from the SUBTLEX-UK database: van Heuven et al., 2014), word length (calculated using the Stringi package, Gagolewski, 2020, in R Studio version 1.3.959), age of acquisition (Kuperman et al., 2012), and concreteness ratings (Brysbaert et al. (2014). Coverage for the 
three variables differed: word frequencies were available for 2100 (86\%) items, word length for all (100\%) items, age of acquisition ratings for 1763 (72\%) items, and concreteness ratings for 1895 (77\%) items.

Table 3.

Summary statistics for category production measures and psycholinguistic variables in concrete and abstract categories (referential version of norms, excluding idiosyncratic items), with total number of items for each measure and the mean and standard deviation.

\begin{tabular}{lcccccc}
\hline Variable & \multicolumn{3}{c}{ Abstract categories } & \multicolumn{3}{c}{ Concrete categories } \\
\cline { 2 - 7 } & $N$ & Mean & SD & $N$ & Mean & SD \\
\hline Category level & & & & & & \\
Category size & 973 & 19.46 & 9.60 & 1478 & 22.06 & 10.88 \\
Mean number of responses & 5785 & 5.98 & 2.73 & 8899 & 6.82 & 3.23 \\
& & & & & & \\
Item level & & & & & & \\
Production frequency & 973 & 5.95 & 5.20 & 1478 & 6.02 & 4.80 \\
Mean rank & 973 & 6.02 & 3.56 & 1478 & 6.72 & 3.74 \\
First-rank frequency & 276 & 3.23 & 3.78 & 400 & 3.11 & 3.47 \\
RT (seconds) first response & 276 & 4.14 & 2.62 & 400 & 3.31 & 1.61 \\
Typicality rating & 734 & 4.26 & 0.59 & 1222 & 4.13 & 0.71 \\
& & & & & & \\
Psycholinguistic variables & & & & & & \\
Word frequency & 816 & 3.86 & 0.93 & 3.80 & 0.78 & 0.78 \\
Word length & 973 & 7.99 & 3.12 & 1478 & 6.68 & 2.57 \\
Age of acquisition & 657 & 8.06 & 2.98 & 1106 & 7.09 & 2.83 \\
Concreteness & 721 & 3.47 & 0.98 & 304 & 4.69 & 0.38 \\
\hline
\end{tabular}




\section{Results \& Discussion}

Table 3 shows summary statistics for all variables across concrete and abstract categories.

Overall, concrete categories were larger in size than abstract categories, containing on average 2.5 more member concepts per category (see Figure 6). The largest concrete category was ANIMAL, at 69 member concepts, but this category was something of an outlier in its size (see Figure 2). The next-largest concrete categories were CLOTHING (47 members) and PART OF THE BODY (45 members), which were comparable with the largest abstract categories of SPORT (46 members) and PROFESSION (43

members). Following the same pattern, participants tended to produce slightly more member concepts for concrete categories than abstract, but the mean difference was less than one member per category.

\section{Figure 6.}

Density plots of category size for abstract and concrete categories.

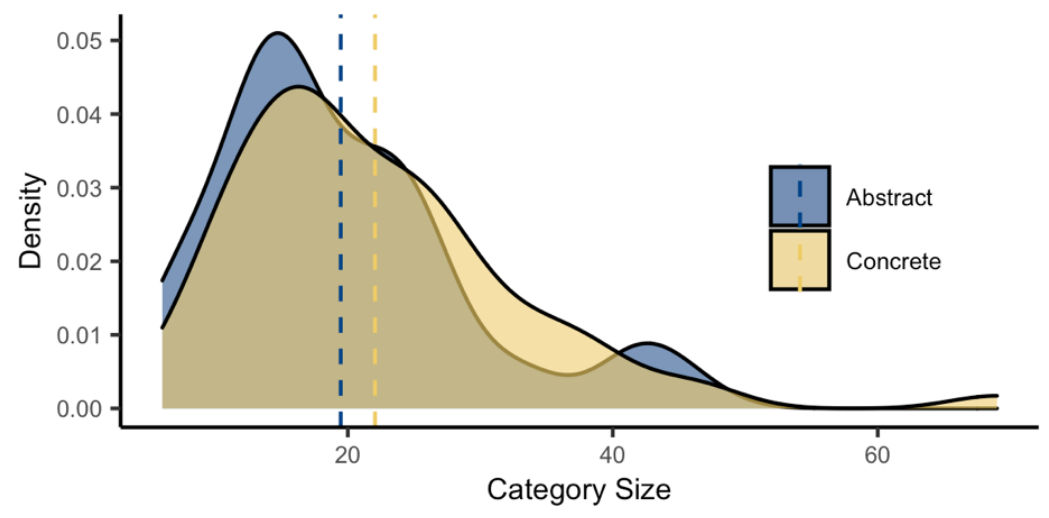

Note. Dotted lines indicate mean values.

At the item level, Figure 7 shows density plots for the four measures of category production and typicality rating for concrete and abstract categories. There were no clear differences in how frequently member concepts were named for their category (i.e., production frequency) or in how often particular concepts tended to be named first for their category (i.e., first-rank frequency). In mean rank, abstract categories had a slightly lower mean than concrete categories (i.e., member concepts tended to be named in earlier ordinal positions), which likely reflects the fact that participants tended to list fewer 
member concepts for abstract categories. The largest difference occurred in RT for first-named member concepts, where participants were approximately $800 \mathrm{~ms}$ slower to produce a response for abstract categories than for concrete categories, implying that abstract category members were more effortful to produce than concrete. Lastly, typicality ratings were slightly higher (i.e., more typical) for abstract category members than for concrete; that is, participants tended to produce "better" examples of abstract categories than of concrete categories. This pattern could arguably be related to category size, whereby the larger concrete categories were more likely to include unusual members than the relatively smaller abstract categories. Very few members of abstract categories were extremely low in typicality (i.e., $\leq 2$ on the $1-5$ typicality scale; e.g., the lowest rating of 1.83 was for nine as a PRIME NUMBER), whereas concrete categories contained several members with low typicality (e.g., rating of 1.17 for cupboard as a ROOM IN A HOUSE; or 1.42 for rabbit as a RODENT). 


\section{Figure 7.}

Density plots of category production measures and typicality for abstract and concrete category members
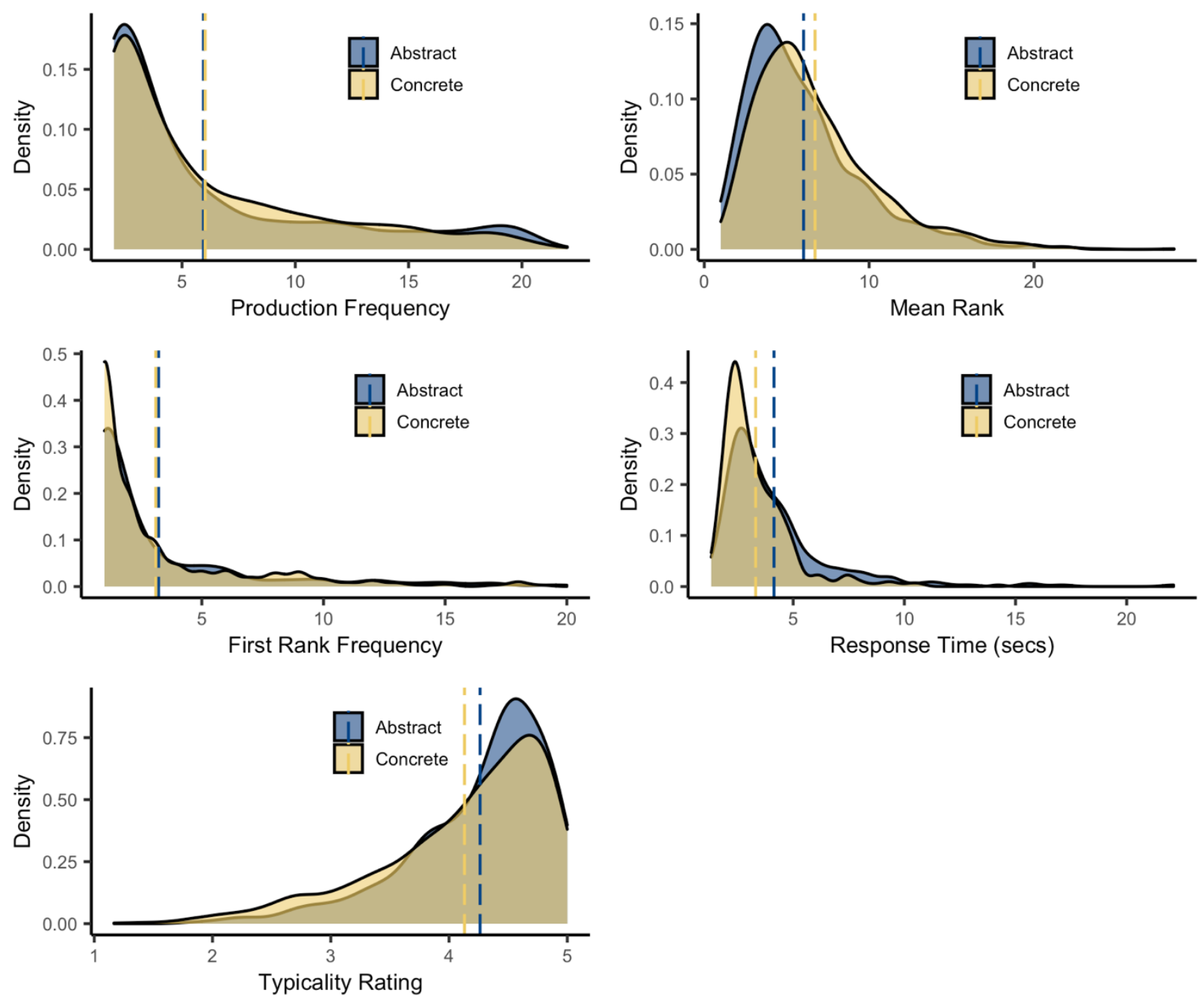

Note. Dotted lines indicate mean values. Since all measures exclude idiosyncratic items, the minimum value for production and first rank frequency is 2 . Response times are for first-named category members only.

In terms of psycholinguistic variables, the differences between concrete and abstract category members were mostly rather small (see Figure 8). There was no clear difference in word frequency, but abstract category members were on average one letter longer than concrete members. Members of 
abstract categories were acquired on average one year later than members of concrete categories, although (as visible in the density plot) they also had a bimodal distribution: many abstract category members were acquired around the age of 5-6 years, similar to the mode of concrete concepts, but a second peak occurred around 7-8 years.

\section{Figure 8.}

Density plots for psycholinguistic measures of abstract and concrete category members.
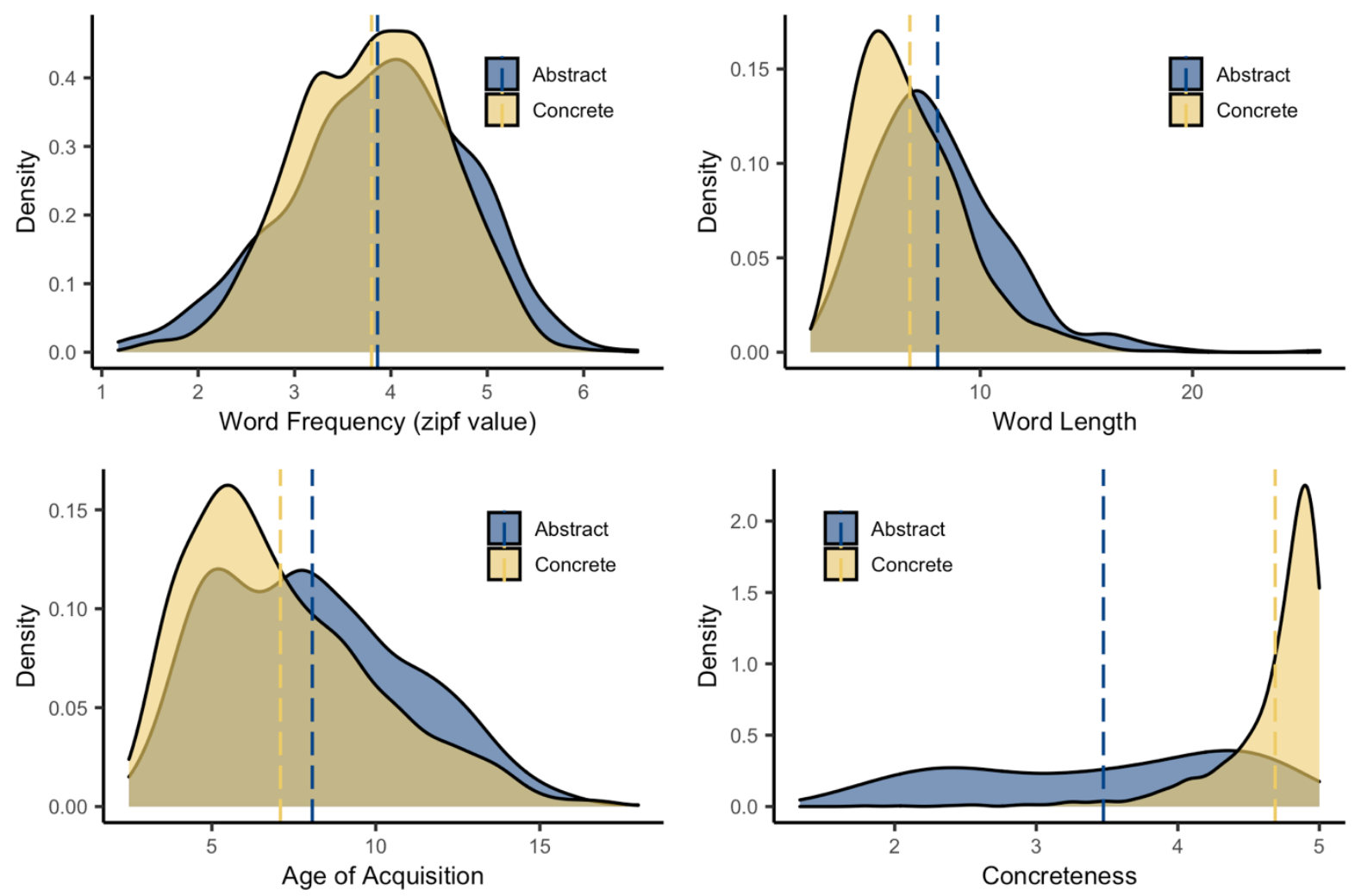

Note. Dotted lines indicate mean values.

Unsurprisingly, the two domains greatly differed in concreteness, with abstract category members having a much lower mean concreteness rating than concrete category members. Abstract category members also had a much flatter distribution across the concreteness scale, which meant somewhat counterintuitively - that many members of abstract categories were actually highly concrete. For example, $13 \%$ of abstract category members had ratings of 4.5 or above on the $1-5$ concreteness 
scale (e.g., PROFESSION - teacher; SPORT - ice skating; GEOMETRIC SHAPE - rectangle). Indeed, when the average concreteness of each category was calculated as the mean rating of its constituent member concepts (see Figure 9), 72\% of abstract categories contained concrete members on average (i.e., the categories had a mean rating above the midpoint of 3 on the 1-5 scale), for example DAY OF THE WEEK, PRIME NUMBER, and SPORT. By comparison, all concrete categories contained concrete members on average, and some $64 \%$ of concrete category members were highly concrete (i.e., rated above 4.5 ). The relative differences in overall concreteness are further illustrated in Figure 9, which plots all 117 categories ordered by their mean concreteness rating per category. A clear distinction between concrete and abstract categories is apparent but is not as clear-cut as might be expected. Many categories traditionally defined as concrete are indeed at the highest end of the scale (e.g., ANIMAL, FRUIT, VEGETABLE, FURNITURE, TOOL), and many clearly abstract categories are at the lowest end of the scale (e.g., PERSONAL QUALITY, EMOTION, RELIGION, POLITICAL SYSTEM, UNIT OF TIME). Nonetheless, the average concreteness of many abstract categories was still relatively high and comparable to that of concrete categories (e.g., THREE-DIMENSIONAL SHAPE, RACKET SPORT) and, conversely, some concrete categories had average concreteness comparable to many abstract categories (e.g., DRUG, WEATHER). In other words, the abstract nature of a category does not necessarily reflect the abstractness of its member concepts, which may be due at least in part to the role of relations in forming certain categorical groups (e.g., Gentner \& Kurtz, 2005; Rehder \& Ross, 2001). 
Figure 9.

Polar plot showing mean concreteness rating per category (ordered lowest to highest clockwise) for concrete and abstract categories.

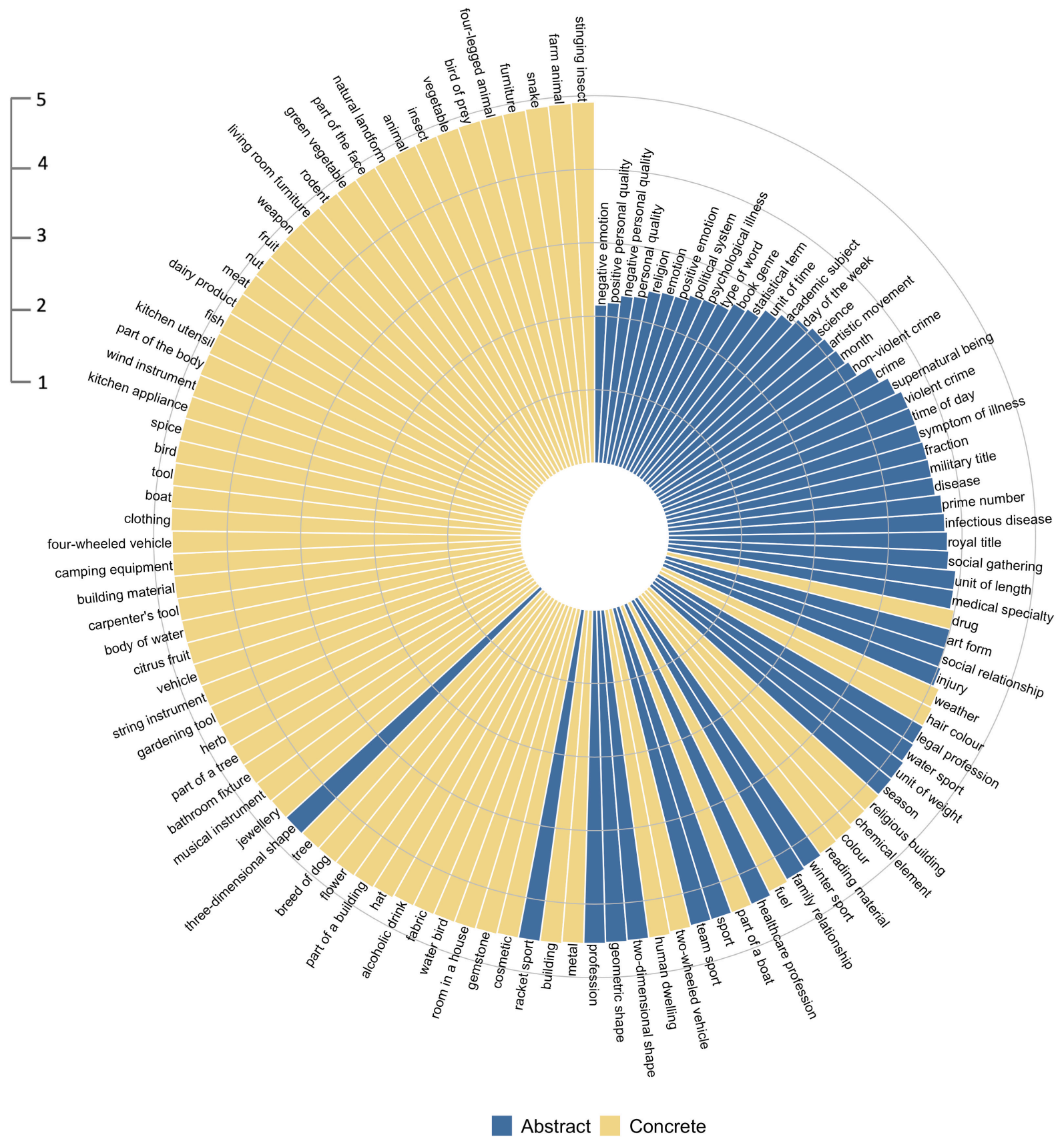




\section{Conclusion}

We provide the first comprehensive set of UK category production norms for a large number of concrete and abstract categories, including two category-level measures (category size and mean number of responses) and five item-level measures (production frequency, mean rank, first-rankfrequency, response times to the first-named members, plus separately-normed typicality ratings for most items). In addition, we provide two versions of the norms: a referential version that groups together responses relating to the same core referent, and a full version that retains all lexical variations in responses as produced by participants. We also provide the trial-level data for each participant, including original voice recordings where consent allows, to enable more detailed analyses. These norms represent a timely update and extension of previous category production norms from the UK, which capture important regional differences in category structure compared to contemporary USA, and generational differences within the UK over the last 35 years. Finally, the norms incorporate an extensive set of abstract categories; we provide the first comparison of category production norms for concrete and abstract categories, highlighting structural and psycholinguistic differences between them, and observing that the constituent members of abstract categories can in fact be highly concrete. We hope that the norms and analyses will be of interest and use to a broad range of researchers in cognitive psychology, neuropsychology, psycholinguistics, cognitive modelling, and any field interested in semantic category structure or the process of producing category members. 


\section{Declarations}

\section{Open Practices Statement}

All materials and data, including original participant recordings, are available at https://osf.io/jgcu6/. No analyses were pre-registered.

\section{Funding}

This work is part of a project that has received funding from the European Research Council (ERC) under the European Union's Horizon 2020 research and innovation programme (Grant agreement No. 682848) to LC.

\section{Conflicts of Interest}

The authors have no conflicts of interest to declare that are relevant to the content of this article.

\section{Ethics Approval}

The studies reported here received ethical approval from the Lancaster University Faculty of Science and Technology Research Ethics Committee.

\section{Consent to Participate}

Informed consent was obtained from all individual participants included in the study.

\section{Consent for Publication}

Informed consent was obtained from all individual participants included in the study.

\section{Availability of Data and Materials}

All images, code, and data presented in this article, including original participant recordings, are available at https://osf.io/jgcu6/, and licensed under a Creative Commons Attribution 4.0 International License (CC-BY), which permits use, sharing, adaptation, distribution, and reproduction in any medium or format, as long as you give appropriate credit to the original author(s) and the source, provide a link to the Creative Commons license, and indicate if changes were made. 


\section{Code Availability}

The code used in this study is available at https://osf.io/jgcu6/.

\section{Acknowledgements}

We thank Victor Kuperman for permission to include the Kuperman et al. (2012) Age of Acquisition ratings in the norms we present here. 


\section{References}

Aizpurua, A., \& Lizaso, I. (2015). Datos normativos para respuestas a categorías semánticas en castellano en adultos jóvenes y mayores. [Normative data for responses to Spanish semantic categories in younger and older adults.]. Psicológica, 36(2), 205-263.

Armstrong, S. L., Gleitman, L. R., \& Gleitman, H. (1983). What some concepts might not be. Cognition, 13(3), 263-308. https://doi.org/10.1016/0010-0277(83)90012-4

Baldo, J. V., \& Shimamura, A. P. (1998). Letter and category fluency in patients with frontal lobe lesions. Neuropsychology, 12(2), 259-267. https://doi.org/10.1037/0894-4105.12.2.259

Balota, D. A., Yap, M. J., Hutchison, K. A., Cortese, M. J., Kessler, B., Loftis, B., Neely, J. H., Nelson, D. L., Simpson, G. B., \& Treiman, R. (2007). The English Lexicon Project. Behavior Research Methods, 39(3), 445-459. https://doi.org/10.3758/BF03193014

Banks, B., Connell, L., \& Wingfield, C. (2020). Linguistic Distributional Knowledge and Sensorimotor Grounding both Contribute to Semantic Category Production. PsyArXiv. https://doi.org/10.31234/osf.io/7eucw

Battig, W. F., \& Montague, W. E. (1969). Category norms of verbal items in 56 categories A replication and extension of the Connecticut category norms. Journal of Experimental Psychology, 80(3, Pt.2), 1-46. https://doi.org/10.1037/h0027577

Binney, R. J., Zuckerman, B. M., Waller, H. N., Hung, J., Ashaie, S. A., \& Reilly, J. (2018). Cathodal tDCS of the Bilateral Anterior Temporal Lobes Facilitates Semantically-Driven Verbal Fluency. Neuropsychologia, 111, 62-71. https://doi.org/10.1016/j.neuropsychologia.2018.01.009

Boersma, P., \& Weenink, D. (2018). Praat: Doing phonetics by computer. In Retrieved October 2017 from http://www.praat.org/(6.0.31).

Bokat, C. E., \& Goldberg, T. E. (2003). Letter and category fluency in schizophrenic patients: A metaanalysis. Schizophrenia Research, 64(1), 73-78. https://doi.org/10.1016/S0920-9964(02)00282-7

Bordignon, S., Zibetti, M. R., Trentini, C. M., Resende, A. C., Minervino, C. A. S. M., Silva-Filho, J. H. da, Pawlowski, J., Teodoro, M. L. M., \& Abreu, N. (2015). Normas de associação semântica para 
20 categorias em adultos e idosos. Psico-USF, 20, 97-108. https://doi.org/10.1590/141382712015200109

Borghi, A. M., Binkofski, F., Castelfranchi, C., Cimatti, F., Scorolli, C., \& Tummolini, L. (2017). The challenge of abstract concepts. Psychological Bulletin, 143(3), 263-292. https://doi.org/10.1037/bu10000089

Brébian, G., Bressan, R. A., Ohlsen, R. I., Pilowsky, L. S., \& David, A. S. (2010). Production of atypical category exemplars in patients with schizophrenia. Journal of the International Neuropsychological Society, 16(5), 822-828. https://doi.org/10.1017/S1355617710000664

Brown, W. P. (1972). Studies in word listing: Some norms and their reliability. The Irish Journal of Psychology, 1(3), 117-159.

Brown, W. P. (1978). A Cross-National Comparison of English-Language Category Norms. Language and Speech, 21(1), 50-68. https://doi.org/10.1177/002383097802100103

Brysbaert, M., Warriner, A. B., \& Kuperman, V. (2014). Concreteness ratings for 40 thousand generally known English word lemmas. Behavior Research Methods, 46(3), 904-911. https://doi.org/10.3758/s13428-013-0403-5

Bueno, S., \& Megherbi, H. (2009). French categorization norms for 70 semantic categories and comparison with Van Overschelde et al.’s (2004) English norms. Behavior Research Methods, 41(4), 1018-1028. https://doi.org/10.3758/BRM.41.4.1018

Capitani, E., Laiacona, M., Mahon, B., \& Caramazza, A. (2003). What are the facts of semantic categoryspecific deficits? A critical review of the clinical evidence. Cognitive Neuropsychology, 20(3), 213-261. https://doi.org/10.1080/02643290244000266

Casey, P. J., \& Heath, R. A. (1988). Category norms for australians. Australian Journal of Psychology, 40(3), 323-339. https://doi.org/10.1080/00049538808260053

Castro, N., Curley, T., \& Hertzog, C. (2021). Category norms with a cross-sectional sample of adults in the United States: Consideration of cohort, age, and historical effects on semantic categories. Behavior Research Methods, 53(2), 898-917. https://doi.org/10.3758/s13428-020-01454-9 
Chan, R. C. K., Wong, M., Chen, E. Y. H., \& Lam, L. C. W. (2003). Semantic Categorisation and Verbal Fluency Performance in a Community Population in Hong Kong: A Preliminary Report Study. Hong Kong Journal of Psychiatry, 13(4), 14-20.

Cohen, B. H., Bousfield, W. A., \& Whitmarsh, G. A. (1957). Cultural norms for verbal items in 43 categories. Technical Report No. 22, University of Connecticut, Contract Nonr. 631(00), Office of Naval Research.

Cohen, J., Cohen, P., West, S. G., \& Aiken, L. S. (2013). Applied Multiple Regression/Correlation Analysis for the Behavioral Sciences. Routledge.

Connell, L., Lynott, D., \& Banks, B. (2018). Interoception: The forgotten modality in perceptual grounding of abstract and concrete concepts. Philosophical Transactions of the Royal Society B: Biological Sciences, 373(1752). https://doi.org/10.1098/rstb.2017.0143

Crowe, S. J., \& Prescott, T. J. (2003). Continuity and change in the development of category structure: Insights from the semantic fluency task. International Journal of Behavioral Development, 27(5), 467-479. https://doi.org/10.1080/01650250344000091

Desai, R. H., Reilly, M., \& van Dam, W. (2018). The multifaceted abstract brain. Philosophical Transactions of the Royal Society B: Biological Sciences, 373(1752), 20170122. https://doi.org/10.1098/rstb.2017.0122

Dubois, D. (1983). Analyse de 22 catégories sémantiques du Français: Organisation catégorielle, lexique et représentation. [An analysis of 22 semantic French categories: Categorical organization, lexicon and representation.]. L'Année Psychologique, 83(2), 465-489. https://doi.org/10.3406/psy.1983.28477

Federmeier, K. D., Kutas, M., \& Schul, R. (2010). Age-related and individual differences in the use of prediction during language comprehension. Brain and Language, 115(3), 149-161. https://doi.org/10.1016/j.bandl.2010.07.006 
Ferreira, C. S., Maraver, M. J., Hanslmayr, S., \& Bajo, T. (2019). Theta oscillations show impaired interference detection in older adults during selective memory retrieval. Scientific Reports, 9(1), 9977. https://doi.org/10.1038/s41598-019-46214-8

Fisk, J. E., \& Sharp, C. A. (2004). Age-related impairment in executive functioning: Updating, inhibition, shifting, and access. Journal of Clinical and Experimental Neuropsychology, 26(7), 874-890. https://doi.org/10.1080/13803390490510680

Gagolewski, M. (2020). stringi: Fast and portable character string processing in $\quad R$ (1.4.6) [Computer software]. https://stringi.gagolewski.com/

Gentner, D., \& Kurtz, K. J. (2005). Relational categories. In Categorization inside and outside the laboratory: Essays in honor of Douglas L. Medin (pp. 151-175). American Psychological Association. https://doi.org/10.1037/11156-009

Hampton, J. A., \& Gardiner, M. M. (1983). Measures of internal category structure: A correlational analysis of normative data. British Journal of Psychology, 74(4), 491-516. https://doi.org/10.1111/j.2044-8295.1983.tb01882.x

Henry, J. D., \& Crawford, J. R. (2004). A meta-analytic review of verbal fluency performance following focal cortical lesions. Neuropsychology, 18(2), 284-295. https://doi.org/10.1037/08944105.18.2.284

Howard, D. V. (1980). Category norms: A comparison of the Battig and Montague (1969) norms with the responses of adults between the ages of 20 and 80. Journal of Gerontology, 35(2), 225-231. https://doi.org/10.1093/geronj/35.2.225

Hunt, K. P., \& Hodge, M. H. (1971). Category-item frequency and category-name meaningfulness (m'): Taxonomic norms for 84 categories. Psychonomic Monograph Supplements, 4(6), 97-121.

Izura, C., Hernández-MuÑoz, N., \& Ellis, A. W. (2005). Category norms for 500 Spanish words in five semantic categories. Behavior Research Methods, 37(3), 385-397. https://doi.org/10.3758/BF03192708 
Jahncke, H., Hongisto, V., \& Virjonen, P. (2013). Cognitive performance during irrelevant speech:

Effects of speech intelligibility and office-task characteristics. Applied Acoustics, 74(3), 307-316. https://doi.org/10.1016/j.apacoust.2012.08.007

JASP Team. (2020). JASP (0.14.1) [Computer software].

Kantner, J., \& Lindsay, D. S. (2014). Category exemplars normed in Canada. Canadian Journal of Experimental Psychology = Revue Canadienne De Psychologie Experimentale, 68(3), 163-165. https://doi.org/10.1037/cep0000023

Kuperman, V., Stadthagen-Gonzalez, H., \& Brysbaert, M. (2012). Age-of-acquisition ratings for 30,000 English words. Behavior Research Methods, 44(4), 978-990. https://doi.org/10.3758/s13428-012$0210-4$

Larochelle, S., Richard, S., \& Souliëres, I. (2000). What Some Effects Might not be: The Time to Verify Membership in "Well-Defined" Categories. The Quarterly Journal of Experimental Psychology Section A, 53(4), 929-961. https://doi.org/10.1080/713755940

Léger, L., Boumlak, H., \& Tijus, C. (2008). BASETY: Extension et typicalité des exemplaires pour 21 catégories d'objets. Canadian Journal of Experimental Psychology, 62(4), 223-232. https://doi.org/10.1037/a0012885

Loess, H., Brown, A., \& Campbell, J. (1969). Cultural norms for items in 30 taxonomic categories. Psychonomic Monograph Supplements, 3(7), 69-86.

Luo, L., Luk, G., \& Bialystok, E. (2010). Effect of language proficiency and executive control on verbal fluency performance in bilinguals. Cognition, 114(1), 29-41. https://doi.org/10.1016/j.cognition.2009.08.014

Mannhaupt, H.-R. (1983). Produktionsnormen für verbale Reaktionen zu 40 geläufigen Kategorien. [German category norms for verbal items in 40 categories.]. Sprache \& Kognition, 2(4), 264-278.

Marchal, A., \& Nicolas, S. (2003). Normes de production catégorielle pour 38 catégories sémantiques: Étude sur des sujets jeunes et âgés. L'Année psychologique, 103(2), 313-366. https://doi.org/10.3406/psy.2003.29639 
Marchenko, O. (2011). Psycholinguistic Database for Russian Language. Proceedings of the European Conference on Cognitive Science. European perspectives on cognitive science, Sophia, Bulgaria.

Marchenko, O., Pavlov, Y., \& Bandurka, T. (2015). Geographical Stability of Generation Frequency Norms for Russian Language. EuroAsianPacific Joint Conference on Cognitive Science, Torino, Italy.

Marful, A., Díez, E., \& Fernandez, A. (2015). Normative data for the 56 categories of Battig and Montague (1969) in Spanish. Behavior Research Methods, 47(3), 902-910. https://doi.org/10.3758/s13428-014-0513-8

Marshall, C. E., \& Parr, W. V. (1996). New Zealand norms for a subset of Battig and Montague's (1969) categories. New Zealand Journal of Psychology, 25(1), 24-29.

McDowd, J., Hoffman, L., Rozek, E., Lyons, K. E., Pahwa, R., Burns, J., \& Kemper, S. (2011). Understanding verbal fluency in healthy aging, Alzheimer's disease, and Parkinson's disease. Neuropsychology, 25(2), 210-225. https://doi.org/10.1037/a0021531

McEvoy, C. L., \& Nelson, D. L. (1982). Category Name and Instance Norms for 106 Categories of Various Sizes. The American Journal of Psychology, 95(4), 581. https://doi.org/10.2307/1422189

Mervis, C. B., Catlin, J., \& Rosch, E. (1976). Relationships among goodness-of-example, category norms, and word frequency. Bulletin of the Psychonomic Society, 7(3), 283-284. https://doi.org/10.3758/BF03337190

Montefinese, M., Ambrosini, E., Fairfield, B., \& Mammarella, N. (2013). Semantic memory: A featurebased analysis and new norms for Italian. Behavior Research Methods, 45(2), 440-461. https://doi.org/10.3758/s13428-012-0263-4

Morrow, L. I., \& Duffy, M. F. (2005). The representation of ontological category concepts as affected by healthy aging: Normative data and theoretical implications. Behavior Research Methods, 37(4), 608-625. https://doi.org/10.3758/BF03192731 
Ober, B. A., Shenaut, G. K., Jagust, W. J., \& Stillman, R. C. (1991). Automatic semantic priming with various category relations in Alzheimer's disease and normal aging. Psychology and Aging, 6(4), 647-660. https://doi.org/10.1037/0882-7974.6.4.647

Osherson, D. N., \& Smith, E. E. (1981). On the adequacy of prototype theory as a theory of concepts. Cognition, 9(1), 35-58. https://doi.org/10.1016/0010-0277(81)90013-5

Pascual Llobell, J., \& Musitu Ochoa, G. (1980). Normas categoriales. [Categorical norms.]. Psicológica, $1(2), 157-174$.

Piñeiro, A., Morenza, L., Torres, M. del R., \& Sierra, C. (1999). Estudio normativo de veinte categorías semánticas en niños y adultos. Revista de psicología general y aplicada: Revista de la Federación Española de Asociaciones de Psicología, 52(1), 147-157.

Pinto, A. C. (1992). Medidas de categorização: Frequência de produção e de tipicidade. [Category norms: Production, frequency, and typicality measures.]. Jornal de Psicologia, 10(3), 10-15.

Plant, C., Webster, J., \& Whitworth, A. (2011). Category norm data and relationships with lexical frequency and typicality within verb semantic categories. Behavior Research Methods, 43(2), 424-440. https://doi.org/10.3758/s13428-010-0051-y

Ponari, M., Norbury, C. F., \& Vigliocco, G. (2020). The role of emotional valence in learning novel abstract concepts. Developmental Psychology, 56(10), 1855-1865. https://doi.org/10.1037/dev0001091

Princeton University. (2010). About WordNet. WordNet. https://wordnet.princeton.edu/

Quaranta, D., Caprara, A., Piccininni, C., Vita, M. G., Gainotti, G., \& Marra, C. (2016). Standardization, Clinical Validation, and Typicality Norms of a New Test Assessing Semantic Verbal Fluency. Archives of Clinical Neuropsychology: The Official Journal of the National Academy of Neuropsychologists, 31(5), 434-445. https://doi.org/10.1093/arclin/acw034

Raz, N., Gunning-Dixon, F. M., Head, D., Dupuis, J. H., \& Acker, J. D. (1998). Neuroanatomical correlates of cognitive aging: Evidence from structural magnetic resonance imaging. Neuropsychology, 12(1), 95-114. https://doi.org/10.1037/0894-4105.12.1.95 
Rehder, B., \& Ross, B. H. (2001). Abstract coherent categories. Journal of Experimental Psychology: Learning, Memory, and Cognition, 27(5), 1261-1275. https://doi.org/10.1037/02787393.27.5.1261

Rohrer, D., Wixted, J. T., Salmon, D. P., \& Butters, N. (1995). Retrieval from semantic memory and its implications for Alzheimer's disease. Journal of Experimental Psychology. Learning, Memory, and Cognition, 21(5), 1127-1139. https://doi.org/10.1037//0278-7393.21.5.1127

Rosch, E. (1973). Natural categories. Cognitive Psychology, 4(3), 328-350. https://doi.org/10.1016/00100285(73)90017-0

Rosch, E. (1975). Cognitive Representations of Semantic Categories. Journal of Experimental Psychology: General, 104(3), 192-233.

Rosch, E., Simpson, C., \& Miller, R. S. (1976). Structural bases of typicality effects. Journal of Experimental Psychology: Human Perception and Performance, 2(4), 491-502. https://doi.org/10.1037/0096-1523.2.4.491

Ruts, W., De Deyne, S., Ameel, E., Vanpaemel, W., Verbeemen, T., \& Storms, G. (2004). Dutch norm data for 13 semantic categories and 338 exemplars. Behavior Research Methods, Instruments, \& Computers, 36(3), 506-515. https://doi.org/10.3758/BF03195597

Ryan, L., Cox, C., Hayes, S. M., \& Nadel, L. (2008). Hippocampal activation during episodic and semantic memory retrieval: Comparing category production and category cued recall. Neuropsychologia, 46(8), 2109-2121. https://doi.org/10.1016/j.neuropsychologia.2008.02.030

Scheithe, K., \& Bäuml, K.-H. (1995). Deutschsprachige Normen für Vertreter von 48 Kategorien. [German-language norms for representatives of 48 conceptual categories.]. Sprache \& Kognition, 14(1), 39-43.

Schloerke, B., Cook, D., Larmarange, J., Briatte, F., Marbach, M., Thoen, E., Elberg, A., Toomet, O., Crowley, J., Hofman, H., \& Wickham, H. (2021). GGally: Extension to 'ggplot2' (2.1.1) [Computer software]. https://ggobi.github.io/ggally/index.html 
Schröder, A., Gemballa, T., Ruppin, S., \& Wartenburger, I. (2012). German norms for semantic typicality, age of acquisition, and concept familiarity. Behavior Research Methods, 44(2), 380394. https://doi.org/10.3758/s13428-011-0164-y

Shao, Z., Janse, E., Visser, K., \& Meyer, A. S. (2014). What do verbal fluency tasks measure? Predictors of verbal fluency performance in older adults. Frontiers in Psychology, 5, 772. https://doi.org/10.3389/fpsyg.2014.00772

Shapiro, S. I., \& Palermo, D. S. (1970). Conceptual organization and class membership: Normative data for representatives of 100 categories. Psychonomic Monograph Supplements, 3(11), 107-127.

Soro, J. C., \& Ferreira, M. A. B. (2017). Normas de categorias ad hoc para língua portuguesa. [Portuguese norms for ad hoc categories.]. Psicologia: Revista Da Associação Portuguesa Psicologia, 31(1), 59-68. https://doi.org/10.17575/rpsicol.v31i1.1285

Soto, P., Sebastián, M. V., \& Del Amo, T. (1982). Categorización y datos normativos en España (Colección Monografías, Instituto de Ciencias de la Educación, Universidad Autónoma de Madrid). Ediciones Cantoblanco.

Stadthagen-Gonzalez, H., Imbault, C., Pérez Sánchez, M. A., \& Brysbaert, M. (2017). Norms of valence and arousal for 14,031 Spanish words. Behavior Research Methods, 49(1), 111-123. https://doi.org/10.3758/s13428-015-0700-2

Storms, G. (2001). Flemish category norms for exemplars of 39 categories: A replication of the Battig and Mongtague (1969) category norms. Psychologica Belgica, 41(3), 145-168.

Troyer, A. K. (2000). Normative Data for Clustering and Switching on Verbal Fluency Tasks. Journal of Clinical and Experimental Neuropsychology, 22(3), 370-378. https://doi.org/10.1076/13803395(200006)22:3;1-V;FT370

Troyer, A. K., Moscovitch, M., \& Winocur, G. (1997). Clustering and switching as two components of verbal fluency: Evidence from younger and older healthy adults. Neuropsychology, 11(1), 138146. https://doi.org/10.1037//0894-4105.11.1.138 
Uyeda, K. M., \& Mandler, G. (1980). Prototypicality norms for 28 semantic categories. Behavior Research Methods \& Instrumentation, 12(6), 587-595. https://doi.org/10.3758/BF03201848

van Heuven, W. J. B., Mandera, P., Keuleers, E., \& Brysbaert, M. (2014). Subtlex-UK: A New and Improved Word Frequency Database for British English. Quarterly Journal of Experimental Psychology, 67(6), 1176-1190. https://doi.org/10.1080/17470218.2013.850521

Van Overschelde, J. P., Rawson, K. A., \& Dunlosky, J. (2004). Category norms: An updated and expanded version of the Battig and Montague (1969) norms. Journal of Memory and Language, 50(3), 289-335. https://doi.org/10.1016/j.jml.2003.10.003

Veling, H., \& van Knippenberg, A. (2004). Remembering Can Cause Inhibition: Retrieval-Induced Inhibition as Cue Independent Process. Journal of Experimental Psychology: Learning, Memory, and Cognition, 30(2), 315-318. https://doi.org/10.1037/0278-7393.30.2.315

Vinogradov, S., Ober, B. A., \& Shenaut, G. K. (1992). Semantic priming of word pronunciation and lexical decision in schizophrenia. Schizophrenia Research, 8(2), 171-181. https://doi.org/10.1016/0920-9964(92)90033-2

Warriner, A. B., Kuperman, V., \& Brysbaert, M. (2013). Norms of valence, arousal, and dominance for 13,915 English lemmas. Behavior Research Methods, 45(4), 1191-1207. https://doi.org/10.3758/s13428-012-0314-x

Wickham, H., François, R., Henry, L., \& Müller, K. (2021). dplyr: A Grammar of Data Manipulation (1.0.5) [Computer software]. https://github.com/tidyverse/dplyr

Yoon, C., Feinberg, F., Hu, P., Gutchess, A. H., Hedden, T., Chen, H.-Y. M., Jing, Q., Cui, Y., \& Park, D. C. (2004). Category norms as a function of culture and age: Comparisons of item responses to 105 categories by american and chinese adults. Psychology and Aging, 19(3), 379-393. https://doi.org/10.1037/0882-7974.19.3.379

Zhao, Q., Guo, Q., \& Hong, Z. (2013). Clustering and switching during a semantic verbal fluency test contribute to differential diagnosis of cognitive impairment. Neuroscience Bulletin, 29(1), 75-82. https://doi.org/10.1007/s12264-013-1301-7 


\section{Appendix}

The variables included in category production norms are as follows.

\section{Category-level variables}

A. Category $=$ category name presented to participants

B. Domain $=$ whether category was abstract or concrete

C. category.size $=$ number of unique member concepts (produced by more than one participant) that were named for a given category

D. mean.number.responses $=$ average number of responses produced by each participant per category (total number of non-idiosyncratic participant responses for the category divided by the total number of participants)

E. mean. $R T=$ mean response time of first responses

F. mean.wordfreq.SUBTLEXUK = mean zipf frequency of all category members

G. mean.word.length = mean word length (number of letters) of all category members

H. mean.AoA.Kuperman = mean age of acquisition of all category members

I. mean.concreteness. Brysbaert = mean concreteness rating of all category members

\section{Item-level variables}

A. category $=$ category name presented to participants

B. category.member $=$ member concept produced by participants for that category

C. domain $=$ whether category was abstract or concrete

D. prod.freq $=$ production frequency: number of participants who named a particular member concept within its category 
E. prod.freq.percent $=$ production frequency expressed as a percentage (i.e. divided by total number of participants)

F. mean.rank = mean ordinal position of a particular member concept within its category

G. first.rank.freq = number of participants who named a particular member concept first within its category

H. first.rank.freq.percent $=$ first rank frequency expressed as a percentage (i.e. divided by total number of participants)

I. mean. $R T=$ mean response time (across all participants) of the category member when named as a first response

J. typicality $=$ typicality rating

K. wordfreq.SUBTLEXUK = zipf frequency

L. $\quad$ word.length $=$ number of letters

M. AoA.Kuperman $=$ age of acquisition

N. concreteness. Brysbaert $=$ concreteness rating 